\title{
Research on the Construction of Analytic Hierarchy Process of Cultural Tourism Competitiveness*
}

\author{
Yan Shi \\ School of Foreign Languages \\ Northwest University \\ Xi'an, China
}

\author{
Yuan Gao \\ School of Economics and Management \\ Northwest University \\ Xi'an, China
}

\author{
Ruonan Cao \\ School of Foreign Languages \\ Northwest University \\ Xi'an, China
}

\begin{abstract}
This paper uses the Analytics Hierarchy Process to realize the analysis of cultural tourism competitiveness. First of all, the authors design the questionnaire and carry out the research on valid objects, which realizes the collection of valid information about influential factors on cultural tourism competitiveness. Then the authors categorize and draw out the concept of influential factors for cultural tourism development, determine the importance degree between the two factors through comparison, establish the Analytic Hierarchy Process of cultural tourism competitiveness, and then judge the validity of the analysis result through consistency test. The research results show that in the construction stage, in order to improve the cultural tourism competitiveness, it is necessary to adopt the mode of "moderate development" and "complete development" respectively according to the types of cultural tourism resources. When designing, it's possible to refer to the mature modes of historic sites and cultural towns. In addition, an effective way to realize users' cultural experience and obtain identity recognition should be provided.
\end{abstract}

Keywords-cultural tourism; Analytic Hierarchy Process; analysis of competitiveness

\section{INTRODUCTION}

Cultural tourism is a new form of tourism consisting of visiting historic sites, appreciating the art of different ethnic groups, experiencing traditional culture, tracing the relics of famous people, participating in various cultural activities, etc. [1] China is rich in cultural tourism resources. In 2009, the Ministry of Culture and Tourism issued The Guidance Opinions on Promoting the Combined Development of Culture and Tourism, specifying the policy support for vigorously developing cultural tourism industry [2]. Tourism is closely related to culture, so even tourism behaviors are influenced by many factors but culture still plays a decisive role in it [3]. Cultural tourism behaviors and its driving and

*Fund: This work was supported by the MOE (Ministry of Education in China) Project of Humanities and Social Sciences (Project No.: 18YJA630025). Key R\&D Program Projects of Shaanxi Science and Technology Department (Project No.: 2017GY-082). leading researches on regional economy and development have become hot topics [4].

Cultural tourism has various forms and rich connotation, including Li Bai's intangible cultural heritage of creative writing such as "Walking on the narrow paths of Shu Kingdom is more difficult than climbing up to Heaven" as well as the tangible cultural heritage — the Terracotta Warriors. Such diversity of resources is gathered, which presents the fruits of human culture. Cultural tourism, as the integration and development of cultural resources and tourism, involves many fields and levels such as culture, economy and politics with the characteristics of systematization and complexity. It is urgent to systematically realize the analysis of competitiveness and propose effective decision-making support of competitiveness in order to enhance its innovation capability and maintain its enduring attractiveness and creativity [5].

The Analytic Hierarchy Process (AHP) is a multi-factor decision analysis method combining qualitative and quantitative analysis. It is widely used in the calculation of key index weights of complex systems. Li Zhengbiao and others drew on the "Diamond Model" of Michael Porter, an authority of American competitive strategy research, to construct an index system for evaluating the competitiveness of the cultural industry and evaluated the competitiveness of culture industry in Yunnan Province from 1995 to 2013 by means of AHP [6]. Liao Yuanzheng and others selected relevant evaluation index factor to carry out the model construction, used the Analytic Hierarchy Process to make the quantitative analysis, and obtained each weight of the tourism resource of Ciqikou, the intangible cultural heritage [7]. Taking Xinyang City as an example, Zhang Wei constructed the comprehensive evaluation index system and AHP model of urban tourism environment, and realized the comprehensive evaluation of tourist environment [8]. The above research shows that the AHP model can effectively realize the influence of various factors in target objects, and 
thus realize the construction on the cognitive system of the complex system.

This paper focuses on how to improve the competitiveness of cultural tourism systematically and effectively. A questionnaire survey was conducted on managers, experts and scholars in relevant departments of cultural tourism to analyze the key factors of the index contents affecting the competitiveness of cultural tourism, and the Analytic Hierarchy Process is adopted to calculate the weight of the evaluation index of competitiveness and propose how to enhance the competitiveness of cultural tourism.

\section{CONSTRUCTION OF HIERARCHICAL ANALYSIS PROCESS OF CULTURAL TOURISM COMPETITIVENESS}

\section{A. Questionnaire Design and Collection}

Questionnaire design is divided into three parts. The first part includes interviewees' personal information, such as age, occupation and so on, so as to grasp the objects' familiarity the concept of "cultural tourism" and sample distribution. The second part is used to explore the content and degree of the respondents' preference for the existing classified resources of cultural tourism. The third part investigates the existing problems in cultural tourism.

In order to ensure the validity of the collection of questionnaire contents, this paper aims at the staff of the management department related to culture and tourism resources, experts in the field of the culture protection department, teachers from institutions of higher learning and relevant professional students. A total of 120 questionnaires were issued and 120 were collected, including 96 valid questionnaires, and the basic information of the interviewees was shown in "Fig. 1" and "Fig. 2".

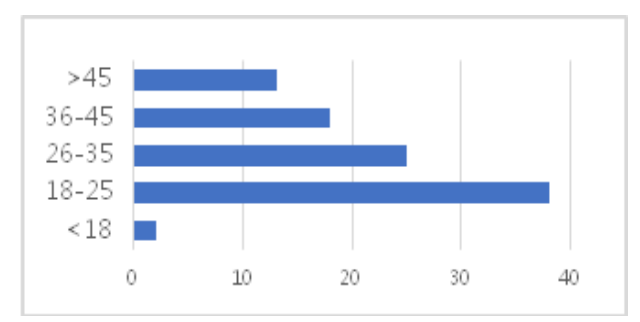

Fig. 1. Statistics on basic information of questionnaire: age distribution

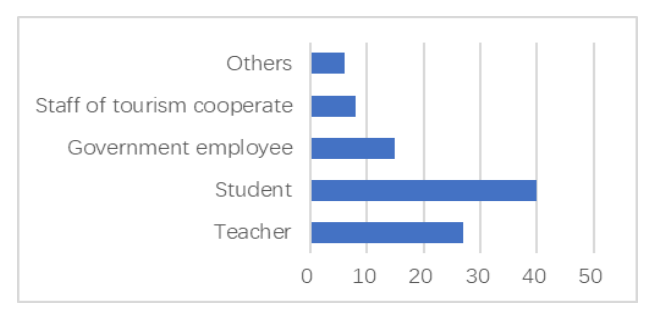

Fig. 2. Statistics on basic information of questionnaire: occupation distribution.

\section{B. The Construction of Competitiveness Analysis Model}

Based on contents of the questionnaire, the concept of evaluation index of cultural tourism competitiveness is extracted, and the evaluation index system is divided into different influence levels by Analytic Hierarchy Process, which are target level, criterion level and factor level. The analysis results are shown in "Table I". The target layer is the target of the whole research content. The criterion level is divided into three categories: existing resource conditions, current development level and landscape development level according to the factors affecting the realization of the target. The factor level is the further refinement index of the criterion layer, belonging to the criterion layer. Through the concept extraction, 18 related factors are extracted in the criterion layer, and the numbers are D1-D18 respectively.

TABLE I. LEVELS OF IMPACT INDICATORS OF CULTURAL TOURISM COMPETITION AND CONSOLIDATION

\begin{tabular}{|c|c|}
\hline \multicolumn{2}{|c|}{ Target level } \\
\hline The competitiveness analysis of the current development of culture \\
tourism
\end{tabular}

\section{Weight Calculation and Consistency Test of Judgment Matrix}

On the basis of the hierarchical structure and the statistical data of the questionnaire, the quantitative analysis of the importance of different influencing factors under the same criterion is further calculated. The concrete steps are as follows:

- According to the established hierarchical process, two-to-two comparisons are made on the influence factors at the factor level under the same judgment criteria, which is based on the assumption that the influence factors at the three criteria levels are consistent.

- Ranking the results of comparison of various factors. The greater the importance is, the greater the weight 
value. In order to ensure that the attached weights here are more scientific, the ratio of the questionnaire results is sorted for weight assignment, and the higher the ratio, the more important it is. In this way, the occurrence of errors can be effectively reduced, and a relatively accurate judgment matrix can be obtained. The weight assignment result is shown in the "Weight" line in "Table II".

- According to the weight matrix calculated in the previous step, a set of eigenvectors corresponding to the maximum eigenvalue (so that the value of the matrix is zero) is further calculated, and then normalized to obtain a set of values reflecting the weight size. This process is called hierarchical single ordering. Hierarchical single rank results are shown in that "eigenvalue" row in "Table II".

TABLE II. WEIGHT CALCULATION RESUltS OF JUdGMENT MATRIX

\begin{tabular}{|c|c|c|c|c|c|c|}
\hline & D1 & D2 & D3 & D4 & D5 & D6 \\
\hline Weight & 5 & 6 & 4 & 3 & 2 & 1 \\
\hline Eigenvalue & 0.079 & 0.094 & 0.063 & 0.047 & 0.032 & 0.016 \\
\hline & D7 & D8 & D9 & D10 & D11 & D12 \\
\hline Weight & 6 & 5 & 7 & 1 & 2 & 4 \\
\hline Eigenvalue & 0.071 & 0.059 & 0.083 & 0.012 & 0.024 & 0.048 \\
\hline & D13 & D14 & D15 & D16 & D17 & D18 \\
\hline Weight & 3 & 1 & 3 & 5 & 2 & 4 \\
\hline Eigenvalue & 0.04 & 0.022 & 0.067 & 0.11 & 0.044 & 0.088 \\
\hline
\end{tabular}

In order to verify the validity of the judgment matrix, SPSS software is used to check the consistency of the matrix, and the test results are shown in "Table III". The value of Cornbach's coefficient is 0.173 , less than the value of 0.2 , and accords with the verification rule, which shows the validity of the method in this paper.

TABLE III. VALIDITY VERIFICATION OF THE JUdGMENT MATRIX

\begin{tabular}{|c|c|}
\hline \multicolumn{2}{|c|}{ Reliability Statistics } \\
\hline Cronbach's Alpha & Items \\
\hline .172 & 3 \\
\hline
\end{tabular}

Through the construction of the Analytic Hierarchy Process, it can be seen that the ranking of the factors that enhance the competitiveness of cultural tourism, and output them according to the descending order of importance. The results are as follows: 【D16 : Moderate development to meet the needs of basic life】 $\rightarrow$ 【D2 : Place of interests】 $\rightarrow$ 【D18 : Complete development to form an integrated business model】 $\rightarrow$ 【D9 : Broaden horizon and mind】 $\rightarrow$ 【 D1 : Cultural ancient towns \ $\rightarrow$ 【 D7 : Overall explanation of tour guidance 】 $\rightarrow$ 【 D15 : A little development, as far as the original ecology $\rightarrow$ 【D3 : Beach Resorts 】 $\rightarrow$ 【 D8 : Strong cultural appeal】 $\rightarrow$ 【D12 : Excellent accommodation environment 】 $\rightarrow$ 【D4 : Nature reserve】 $\rightarrow$ 【D17 : Full development for the convenience of eating, lodging and traveling】 $\rightarrow$

【D13 : Guaranteed security】 $\rightarrow$ 【D5 : City districts】 $\rightarrow$

【D11 : Varied delicious food】 $\rightarrow$ 【D14 : Stay away from development and keep it natural】 $\rightarrow$ 【D6 : Scenic spots】 $\rightarrow$ 【D10 Convenient transportation】.

\section{RESULTS AND COUNTERMEASURES}

In this paper, the evaluation index of cultural tourism competitiveness is calculated by construction on the Analytic Hierarchy Process, and the following conclusions and decision- support suggestions are put forward based on the index system.

First of all, to determine the degree of cultural tourism development is an important factor to reflect the competitiveness of cultural tourism. There are dualism viewpoints of "moderate development to meet the basic needs" and "complete development to form an integrated business model" in the analysis result of the Analytic Hierarchy Process. Through the backtracking and analysis of the contents of questionnaire, it is analytically found that there is a strong correlation between D16 and D2 options, while D18 and D1 strongly correlated to each other. The conclusion shows that the development of cultural tourism resources needs to be adapted to local conditions. As for resources like places of interests, they should be moderately developed with the preservation of its original appearance for the satisfaction of tourists' basic needs. But the construction thought of cultural ancient towns can be the "complete development to form an integrated business model" so as to meet all-round demands of tourists.

At present, compared with other scenic areas, the resources of "places of interests" and "cultural ancient towns" in cultural tourism stand out from the competition and are enjoyed by tourists. It is shown that the development and publicity of these two types of cultural tourism resources are quite sufficient, so when developing other types of resources, the pattern of these two types of resources can be used for reference, combine the characteristics of scenic spots, and strengthen the measures of scenic areas development, so that services of scenic areas to meet the public demands for culture tourism

Users should pay more attention to the spiritual enhancement of cultural tourism resources, and the process of sightseeing often becomes a way to realize self-identity [9]. This conclusion is expressed in the higher ranking of "broadening horizon and mind." Based on the overall explanation to tour guidance and the factors that rank higher, it can be seen that when the cultural tourism resources are developed, the tourists pay attention to knowledge acquisition and cultural experience enhancement. So it is an effective way to improve the competitiveness of cultural tourism with an overall explanation to tour guidance, the indepth quality training of tour guides, the design of guidance for different groups of visitors and the setting of culture peripheral products.

\section{CONCLUSION}

China is in a period of great cultural development and prosperity. Cultural tourism, as an important part of cultural 
cause, should especially be oriented to the public and its development will be promoted to a new climax.

This paper, from the perspective of promoting the comprehensive competitiveness of cultural tourism, constructs the index system of cultural tourism competitiveness through the in-depth questionnaire survey, and obtains the index weight through the hierarchical analysis process. The research shows that the competitiveness of cultural tourism can be improved from the following aspects:

First: The degree of resource development should be adapted to local conditions, which means the places of interest should be developed moderately, while cultural ancient towns can be deeply developed;

Second: Other types of resources can draw on the mode of well-developed places of interest and cultural ancient towns;

Third: Achieving tourists' cultural experience and selfidentity, and providing in-depth and comprehensive explanation to tour guidance for tourists of cultural tourism.

In the next step, it's needed to carry out more in-depth researches from the demand measurement of cultural tourism, combine the needs from real experiences of cultural tourism, conduct their perception analysis, and obtain effective methods to enhance the competitiveness of cultural tourism.

\section{REFERENCES}

[1] Hou Bing, Huang Zhenfang, Xu Haijun. The research of spatial form of cultural tourism - summary and inspiration based on cultural space [J]. Tourism Tribune, 2011(03): 70-77.

[2] The Guidance Opinions on Promoting the Combined Development of Culture and Tourism [EB/OL]. https://baike.baidu.com/item/ Guidance of the National Tourism Administration of the Ministry of Culture on the promotion of the cultural tourism $/ 8408873$.

[3] Marris T. Culture as a determinant of the attractiveness of a tourism region [J]. Annals of Tourism Research, 1978,5(3): 339-340.

[4] Wei Xiao'an. The fourth tourism revolution [J]. Tourism Tribunel, 2018(02): 11-14.

[5] Zhen-chun S, Xiao-jun J I, Lu-ying L V, et al. A Study on the Structure andProperties of Cultural Tourism Innovation System [J]. Tourism Tribune, 2012,27(2): 80-87.

[6] Li Zhenbiao, Xue Yongjun. et al. Evaluation on cultural industry competitiveness based on AHP model - a case study of Yunnan Province [J]. Resources Development and Market, 2016,32(3): 293297.

[7] Liao Yuanzheng, Mao Changyi. Quantitative evaluation on intangible cultural relics tourism resources based on AHP - a case study of Ciqikou in Chongqing [J]. Journal of Chongqing Arts and Sciences Institute, 2015(4): 7-13.

[8] Zhang Wei. A comprehensive evaluation on urban tourism environment based on AHP — a case study of Xinyang City [J]. Urban Geography,2017(4).

[9] Bond N, Falk J. Tourism and identity-related motivations: why am I here (and not there) [J]. International Journal of Tourism Research, 2013,15(5): 430-442. 